\title{
Brewer's Grains with Different Pretreatments Used as Bio-Adsorbents for the Removal of Congo Red Dye from Aqueous Solution
}

Jianguo Wu,* Zhao Zhang, Jintao Xu, Xuanxian Lu, Chi Wang, Hui Xu, Haihang Yuan, and Ji Zhang

\begin{abstract}
Brewer's grains (BG), a by-product of the beer industry, were first pretreated by sulfuric acid, sodium hydroxide, and white-rot fungus Coriolus versicolor for the preparation of bio-adsorbents BGPH, BGPOH, and BGPB, respectively. All bio-adsorbents were rich in hydroxyl groups and could adsorb Congo red dye from aqueous solution, and BGPOH worked better than the others. The order of maximum equilibrium adsorption capacity of bio-adsorbents for Congo red was BGPOH > BGPH $>$ BGPB. The Langmuir, Freundlich, and Temkin adsorption isotherm models all fit well with the experimental data. The negative Gibbs free energy change meant that the adsorption was spontaneous, and lower temperature was useful for the adsorption of Congo red onto the bioadsorbents. The pseudo first-order and second-order kinetics models fit well with the experimental data, and the second-order kinetics model fit better, which indicated the adsorption was controlled by diffusion phenomena. Brewer's grains with the three pretreatments could be used as efficient adsorbents for the treatment of dye wastewater.
\end{abstract}

Keywords: Brewer's grains; Pretreatment; Bio-adsorbent; Congo red; Adsorption isotherm; Adsorption thermodynamics; Adsorption kinetics

Contact information: Jiangsu Key Laboratory for Eco-Agricultural Biotechnology around Hongze Lake, Jiangsu Key Construction Laboratory for Food Safe and Nutritional Function, School of Life Science,

Huaiyin Normal University, Changjiang West Road 111, Huai'an 223300, China;

* Corresponding author: jgwu_21@sina.cn

\section{INTRODUCTION}

Brewer's grains are the main by-product of the beer industry, with a global total of approximately 30 million tons (Mahmood et al. 2013). There are two main ways to deal with brewer's grains: to treat it as a waste, which leads to environmental pollution and waste of resources, or to use it as feed (Imaizumi et al. 2015; Bougrier et al. 2018; Lao et al. 2020). Because of the high protein and cellulose in brewer's grains, some researchers have used it in the production of flakes, whole wheat bread, biscuits, and appetizers, but the added amount of brewer's grains was very small (Hassona 1993; Ktenioudaki et al. 2013; McCarthy et al. 2013; Awolu et al. 2016). Brewer's grains are also used for biorefinery and recovery of polyphenols, but there is still a technical bottleneck for large-scale application (White et al. 2008; Mussatto et al. 2013; Birsan et al. 2019; Rojas-Chamorro et al. 2020). The question remains of how to use brewer's grains in large quantities without complicated pretreatment.

Wastewater is a complex issue in the textile and printing and dyeing industries due to the application of a large number of dyes, which are difficult to degrade. The treatment of printing and dyeing wastewater includes physical adsorption, chemical degradation, and 
biological treatment (Katheresan et al. 2018; Dou et al. 2020; Li et al. 2020; Oliveira et al. 2020). Activated carbon adsorption has become the most commonly used method to treat the wastewater, but the cost was too high because of the expensive price of commercial activated carbon. Therefore, many new low-cost adsorbents have been developed such as hardwood, spent diatomaceous earth, fly ash, sewage sludge, orange peel, and spent mushroom substrates (Tsai et al. 2004; Wu et al. 2018; Chu et al. 2019; Godlewska et al. 2019; Wu et al. 2019; Ahmed et al. 2020; Sun et al. 2020).

Brewer's grains contain a high level of cellulose and lignin, and they have a porous structure, which has the potential to adsorb some pollutants effectively. Brewer's grains have been used to adsorb cadmium and lead in aqueous solution, and the maximum adsorption capacity reaches $17.3 \mathrm{mg} / \mathrm{g}$ and $35.5 \mathrm{mg} / \mathrm{g}$, respectively (Low et al. 2000). Brewer's grains were also used to absorb copper and malachite green, and the adsorption results were also good (Chanzu et al. 2019; Wierzba et al. 2019). Therefore, brewer's grains may be a good adsorbent for wastewater. If brewer's grains could be fully utilized to treat large amounts of printing and dyeing wastewater, the economic and environmental pressure of the printing and dyeing industries could be relieved. However, there are only a few reports on the use of brewer's grains to adsorb dyes.

Pretreated brewer's grains are mostly used in bio-refinery, but seldom used as adsorbent (Zhang and Zang 2016; Lorente et al. 2019; Ashman et al. 2020). Congo red is a kind of acidic dye, which has been widely used in the cotton dyeing and papermaking industries. The wastewater of Congo red dye can cause cancer and pose possible risk of harm to unborn children, so the wastewater seriously endangers human health (Goswami et al. 2020). In this study, the brewer's grains were pretreated by dilute acid, dilute base, and white rot fungus Coriolus versicolor in order to prepare them for removal of Congo red dye from aqueous solution, and the adsorption isotherm, thermodynamics, and kinetics were also studied. The brewer's grains adsorbed Congo red could be bio-pretreated again by $C$. versicolor in order to degrade Congo red and reuse the brewer's grains (Wu et al. 2018).

\section{EXPERIMENTAL}

\section{Preparation of Bio-adsorbents by Pretreatment of Brewer's Grains}

Brewer's grains $(\mathrm{BG})$, the residues from saccharification of malt, were pretreated by $0.1 \mathrm{~mol} / \mathrm{L}$ sulfuric acid (analytical purity) at $121^{\circ} \mathrm{C}$ for $20 \mathrm{~min}$; or pretreated by 0.1 $\mathrm{mol} / \mathrm{L}$ of sodium hydroxide (analytical purity) at $121^{\circ} \mathrm{C}$ for $20 \mathrm{~min}$; or pretreated by whiterot fungus Coriolus versicolor, which was deposited in the Jiangsu Key Laboratory for Eco-Agricultural Biotechnology around Hongze Lake at $28{ }^{\circ} \mathrm{C}$ for 25 days. All brewer's grains were washed by ultrapure water 2 to 3 times and crushed into 100-mesh particles. The bio-adsorbents BGPH, BGPOH, BGPB were obtained from the brewer's grains with sulfuric acid pretreatment, with sodium hydroxide pretreatment, and with biological pretreatment, respectively.

\section{Fourier Transform Infrared (FTIR) Spectroscopy of Bio-adsorbents}

FTIR spectra were determined by Nicolet iS5 FTIR spectrometer (Thermo Scientific, Waltham, MA USA). KBr pellets were prepared with $2 \mathrm{mg}$ of powdered bioadsorbent in $40 \mathrm{mg}$ of $\mathrm{KBr}$ for FTIR spectroscopy. Spectral measurements ranged from $400 \mathrm{~cm}^{-1}$ to $4000 \mathrm{~cm}^{-1}$ with $0.4 \mathrm{~cm}^{-1}$ resolution. 


\section{Batch Bio-adsorption of Congo Red}

To study the effects of bio-adsorbent usage, temperature, and time on the adsorption of Congo red (99\% of purity) onto bio-adsorbents, bio-adsorption was conducted in 250 $\mathrm{mL}$ conical flasks with $100 \mathrm{~mL}$ of $300 \mathrm{mg} / \mathrm{L}$ aqueous solution of Congo red. Batch bioadsorption conditions were shown in Table 1.

Table 1. Batch Bio-adsorption Conditions

\begin{tabular}{|c|c|c|c|}
\hline \multirow{2}{*}{ Adsorption conditions } & \multicolumn{3}{|c|}{ Level } \\
\cline { 2 - 4 } & $\begin{array}{c}\text { Usage of adsorbent } \\
(\mathrm{g})\end{array}$ & $T(\mathrm{~K})$ & $t(\mathrm{~min})$ \\
\hline Usage of adsorbent & $\begin{array}{c}0.1,0.3,0.6,0.8,1.0, \\
1.3,1.6,2\end{array}$ & 313 & 150 \\
\hline Adsorption temperature $(T)$ & 1 & $\begin{array}{c}303,308,313, \\
318,323,328\end{array}$ & 150 \\
\hline Adsorption time $(t)$ & 1 & 313 & $\begin{array}{c}5,10,15,20,25,30, \\
45,60,90,120,150\end{array}$ \\
\hline
\end{tabular}

\section{Determination of Dye Concentration}

The equilibrium suspensions were centrifuged at $7000 \mathrm{r} / \mathrm{min}$ of speed for $10 \mathrm{~min}$, and the concentrations of dye were determined by a UV-vis spectrophotometer (Model 754, Shanghai Sunny Hengping Instrument Co., Ltd., Shanghai, China) with $1 \mathrm{~cm}$ of glass cell at $500 \mathrm{~nm}$ of wavelength. All data were obtained from three times replicated determinations. The adsorption rate $(\mathrm{R} \%)$ of Congo red onto bio-adsorbent was calculated by Eq. 1, and the equilibrium adsorption capacity of bio-adsorbent for Congo red, $\mathrm{Q}_{\mathrm{e}}$ (mg/g), was calculated by Eq. 2,

$$
\begin{aligned}
& R(\%)=\frac{C_{0}-C_{e}}{C_{0}} \times 100 \% \\
& Q_{e}=\left(C_{0}-C_{e}\right) \times \frac{V}{W}
\end{aligned}
$$

where $C_{0}$ and $C_{e}$ are the initial and equilibrium liquid-phase concentrations of Congo red respectively $(\mathrm{mg} / \mathrm{L}), V$ is the volume of the experiment solution $(0.1 \mathrm{~L})$, and $W$ is the amount of bio-adsorbent $(\mathrm{g})$.

\section{Model of Adsorption Isotherm}

A single molecule adsorption theoretical model known as the Langmuir model is shown as Eq. 3, and two empirical adsorption models known as the Freundlich and Temkin models are shown in Eqs. 4 and 5,

$$
\begin{aligned}
& \frac{C_{e}}{Q_{e}}=\frac{C_{e}}{Q_{m}}+\frac{1}{K_{L} \times Q_{m}} \\
& \ln Q_{e}=\frac{1}{n} \ln C_{e}+\ln K_{F} \\
& Q_{e}=\frac{R T}{b_{t}} \ln C_{e}+\frac{R T}{b_{t}} \ln a_{t}
\end{aligned}
$$

where $C_{e}$ is the equilibrium liquid-phase concentration of Congo red (mg/L), $Q_{e}$ and $Q_{m}$ are the equilibrium and maximum adsorbed capacities of Congo red per mass of bioadsorbent respectively $(\mathrm{mg} / \mathrm{g}), K_{L}$ is the Langmuir equilibrium adsorption constant $(\mathrm{L} / \mathrm{mg})$ related to the free energy of adsorption, $K_{F}$ is the Freundlich constant $[(\mathrm{mg} / \mathrm{g})(\mathrm{L} / \mathrm{mg}) 1 / \mathrm{n}]$ related to the strength of the adsorptive bond, $1 / n$ is the adsorption intensity factor or 
surface heterogeneity, $R$ is the molar gas constant $\left(8.314 \mathrm{~J} \cdot \mathrm{mol}^{-1} \cdot \mathrm{K}^{-1}\right), T$ is absolute temperature $(313 \mathrm{~K})$, and $a_{t}$ and $b_{t}$ are the Temkin equilibrium adsorption constants.

\section{Model of Adsorption Thermodynamics}

The Gibbs-Helmholtz equation was used as the model of adsorption thermodynamics in Eq. 6, which could be modified as Eq. 7,

$$
\begin{aligned}
& \Delta G=\Delta H-\Delta S \cdot T \\
& \ln \frac{C_{B e}}{C_{A e}}=-\frac{\Delta H}{R T}+\frac{\Delta S}{R}
\end{aligned}
$$

where $C_{B e}$ and $C_{A e}$ represent the equilibrium concentrations of Congo red in adsorbent and solution $(\mathrm{mg} / \mathrm{L}), \Delta G$ is the Gibbs free energy change $\left(\mathrm{J} \cdot \mathrm{mol}^{-1}\right), \Delta H$ is the adsorption enthalpy change $\left(\mathrm{J} \cdot \mathrm{mol}^{-1}\right), \Delta S$ is the adsorption entropy change $\left(\mathrm{J}^{\mathrm{mol}}{ }^{-1} \cdot \mathrm{K}^{-1}\right), R$ is the molar gas constant $\left(8.314 \mathrm{~J} \cdot \mathrm{mol}^{-1} \cdot \mathrm{K}^{-1}\right)$, and $T$ is absolute temperature $(\mathrm{K})$.

\section{Model of Adsorption Kinetics}

The pseudo first-order (Eq. 8) and second-order kinetics (Eq. 9) (Xu et al. 2019) were used to evaluate the adsorption kinetics as follows,

$$
\begin{aligned}
& \ln \left(Q_{e}-Q_{t}\right)=\ln Q_{e}-k_{1} t \\
& \frac{t}{Q_{t}}=\frac{t}{Q_{e}}+\frac{1}{k_{2} Q_{e}{ }^{2}}
\end{aligned}
$$

where $Q_{e}$ and $Q_{t}$ represent the adsorption capacities $(\mathrm{mg} / \mathrm{g})$ of SSGL at equilibrium and at a particular time $t(\mathrm{~min})$, respectively. The first-order and second-order kinetic rate constants are denoted by $k_{1}(1 / \mathrm{min})$ and $k_{2}[(\mathrm{~g} / \mathrm{mg})(1 / \mathrm{min})]$.

\section{RESULTS AND DISCUSSION}

\section{FTIR Analysis of Bio-adsorbents}

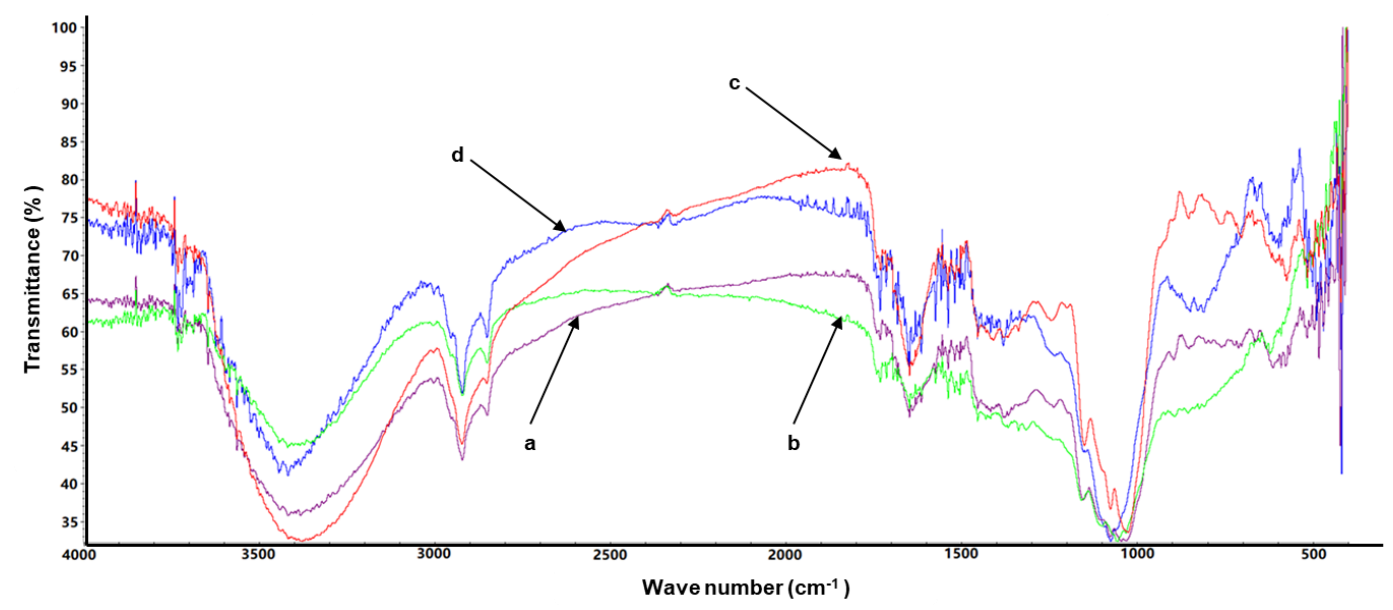

Fig. 1. Fourier transform infrared spectroscopy (FTIR) of bio-adsorbents. Color lines $\mathbf{a}, \mathbf{b}$, and $\mathbf{c}$ represent that of brewer's grains pretreated by dilute sodium hydroxide (BGPOH), dilute sulfuric acid (BGPH), and white-rot fungus (BGPB); Line $\mathbf{d}$ represents that of brewer's grains without pretreatment $(B G)$ 
The differences in chemical bonds among the adsorbents could be clearly found by FTIR of BG, BGPH, BGPOH, and BGPB which are shown in Fig. 1. They were rich of hydroxyl groups ( $3400 \mathrm{~cm}^{-1}$ band) in $\mathrm{BG}$, which may have been caused by the stretching vibration of the $\mathrm{C}-\mathrm{OH}$ bond in cellulose and hemicellulose of BG. The peak at $2926 \mathrm{~cm}^{-1}$ was caused by the asymmetric stretching vibration of $\mathrm{CH}_{3}$, and the peaks at $1730 \mathrm{~cm}^{-1}$ and $1638 \mathrm{~cm}^{-1}$ were from the characteristic stretching vibration of the $\mathrm{C}=\mathrm{O}$ bond in the carboxyl group or the aldehyde and ketone groups. The stretching vibration of the benzene ring skeleton appeared near $1541 \mathrm{~cm}^{-1}$. The peaks at 1160 and $1081 \mathrm{~cm}^{-1}$ were mainly attributed to the stretching vibrations of the $-\mathrm{Si}-\mathrm{O}-\mathrm{Cellulose}$ and $-\mathrm{Si}-\mathrm{O}-\mathrm{Si}$ - bonds respectively (Azlinda et al. 2016).

When brewer's grains were pretreated by dilute sulphuric acid, the contents of the hydroxyl group and methyl group in BGPH were decreased significantly, which indicated hemicellulose in brewer's grains could be hydrolyzed. However, when brewer's grains were pretreated by sodium hydroxide, the stretching vibration of the benzene ring skeleton in BGPOH was weakened, which indicated the lignin in brewer's grains could be degraded by sodium hydroxide. In addition, when brewer's grains were pretreated by white-rot fungus Coriolus versicolor, the stretching vibration of the hydroxyl group in BGPB were enhanced, but the stretching vibration of the benzene ring skeleton was weakened. This indicated that the lignin in brewer's grains was degraded and led to the exposure of cellulose, and the polysaccharide, rich in hydroxyl, which was also produced during biological pretreatment (Wang et al. 2019).

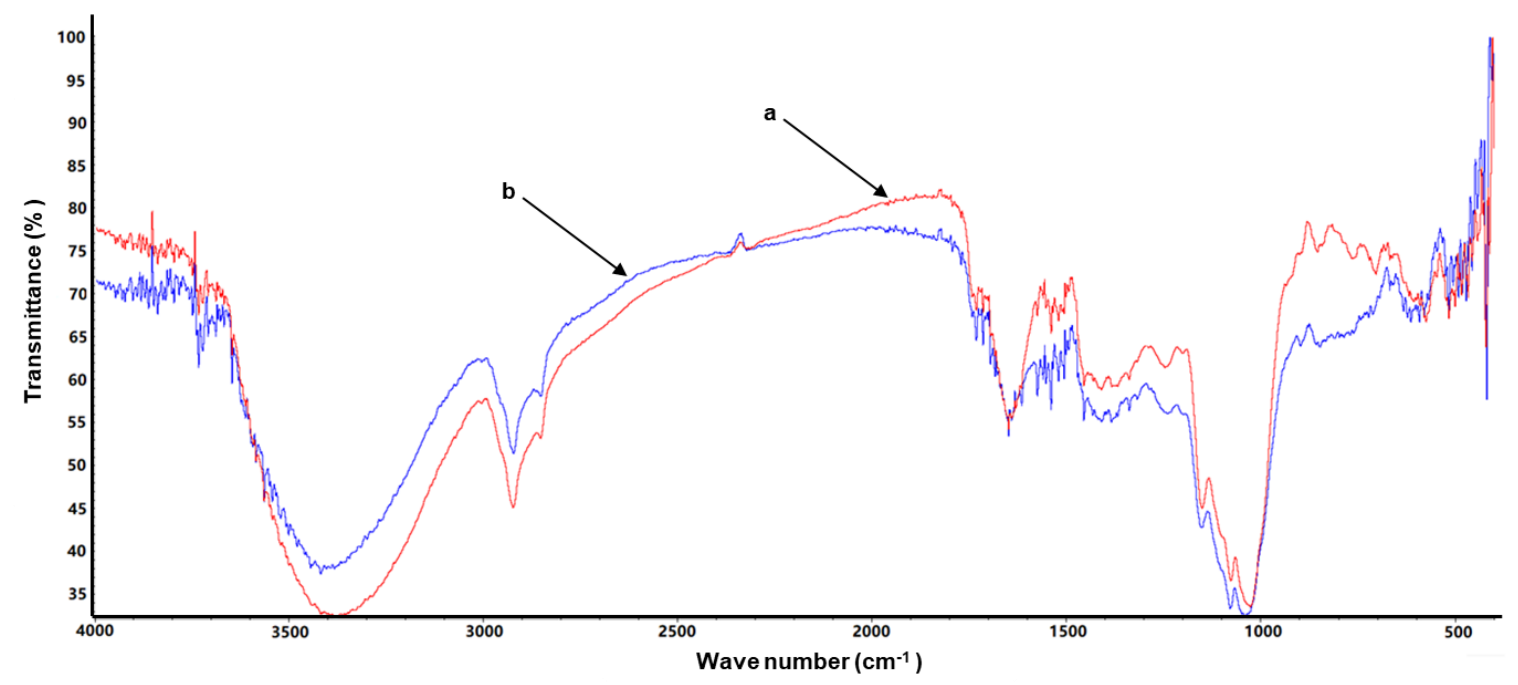

Fig. 2. Fourier transform infrared spectroscopy (FTIR) of BGPB. Line a represents that of BGPB; line $\boldsymbol{b}$ represents that of BGPB after adsorbing Congo red

Congo red, a kind of acidic dye, was adsorbed in aqueous solution by BGPH, $\mathrm{BGPOH}$, and BGPB, which decreased the concentration of Congo red significantly. The FTIR of the bio-adsorbents with Congo red was also determined, and the FTIR of BGPB with Congo red was shown in Fig. 2. The stretching vibration of the benzene ring was enhanced significantly, which indicated that Congo red should be indeed adsorbed onto the adsorbent as Congo red is rich of benzene ring structure. Because the chemical structure of Congo red contains two molecules of amino groups, which may produce hydrogen bond with the hydroxyl groups on the adsorbents and could have led to the adsorption of Congo red by the adsorbents. 


\section{Adsorption of Congo Red by Bio-adsorbents}

When the concentration of Congo red was $300 \mathrm{mg} / \mathrm{L}$, the adsorption levels of Congo red onto BGPH, BGPOH, and BGPB increased with the increase of the usage of bio-adsorbents (ranged from 0.1g to $2 \mathrm{~g}$ ), which was shown in Fig. 3a. Especially when the dosages were only $0.1 \mathrm{~g}$, the adsorption reached more than $50 \%$. Further increasing the usages of bio-adsorbents increased the adsorption extents slowly. The equilibrium adsorption capacity $\left(Q_{\mathrm{e}}\right)$ of bio-adsorbents for Congo red decreased with the increased usage of bio-adsorbents, as shown in Fig. 3b. The $Q_{\mathrm{e}}$ of adsorbents was quite different at low dosage of bio-adsorbents, and the order for the $Q_{\mathrm{e}}$ of bio-adsorbents was BGPOH > $\mathrm{BGPH}>\mathrm{BGPB}$. When the dosage was more than $1.2 \mathrm{~g}$, there was no significant difference among the bio-adsorbents. Therefore, brewer's grains with pretreatments could be used as bio-adsorbents for the removal of Congo red in aqueous solution.

Alkali pretreatment could degrade lignin and make the brewer's grains have a more porous structure, which was more conducive to the adsorption of Congo red onto BGPOH. However, when the pretreatment time of sodium hydroxide was further extended to 2 hours, it was found that the adsorption rate of BGPOH for Congo red was greatly decreased. So, the excessive degradation of lignin in the brewer's grains was not conducive to the adsorption of Congo red. In addition, biological pretreatment could also lead to the degradation and removal of lignin and the porous structure, but it also produced polysaccharides at the same time, which reduced the adsorption of Congo red onto the adsorbent.
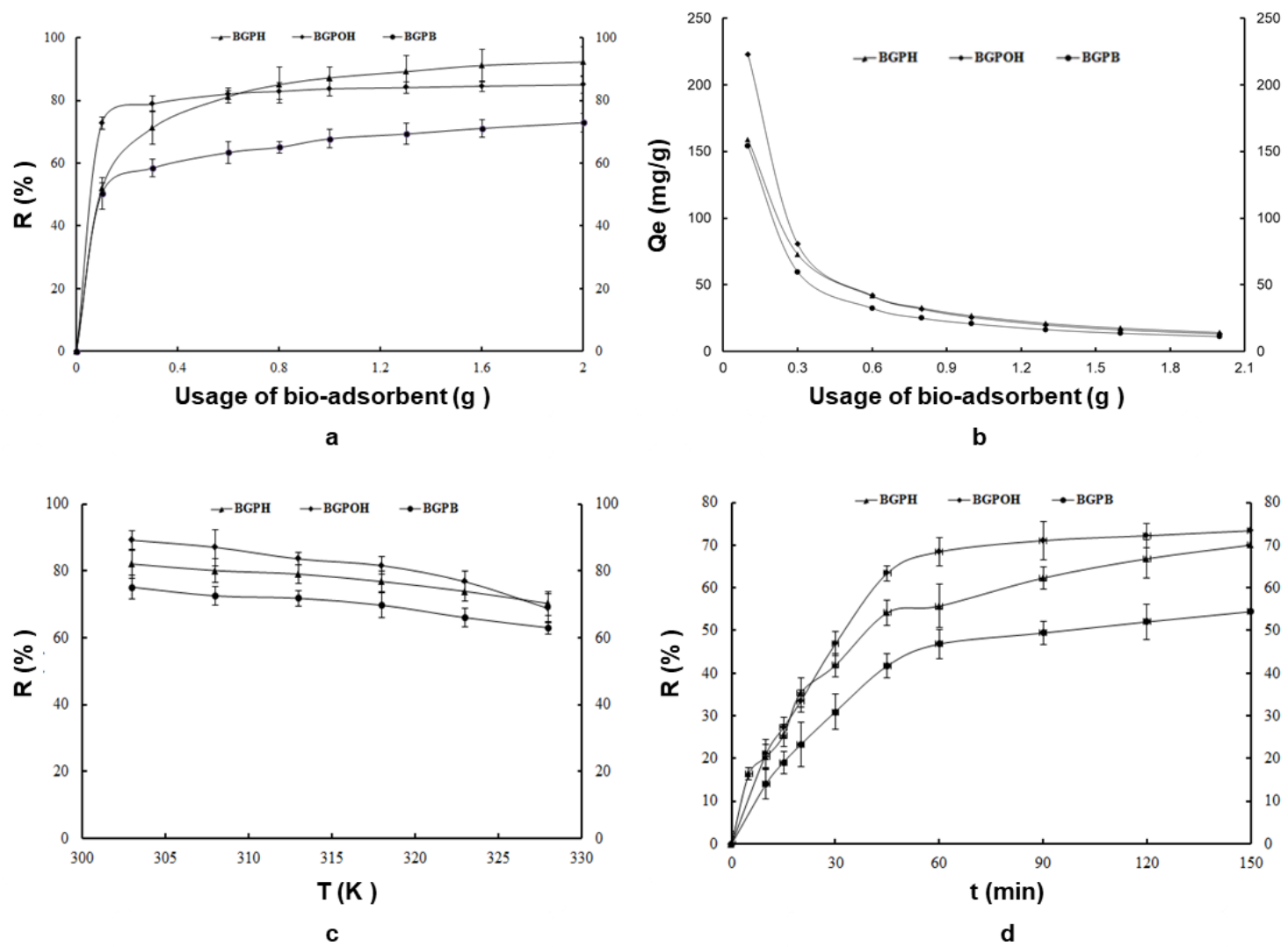

Fig. 3. Effects of usage of bio-adsorbent ( $a$ and b), adsorption temperature (c) and time (d) on the adsorption of Congo red dye onto the bio-adsorbents. 
As shown in Fig. 3c, increasing the adsorption temperature decreased the adsorption rate of Congo red continually, which indicated that high temperature was not conducive to the adsorption of Congo red onto the bio-adsorbents. It was speculated that the adsorption of Congo red onto bio-adsorbents belonged to physical adsorption, and low temperature would be the better choice to adsorb Congo red using the three bio-adsorbents. Adsorption rates of Congo red increased with increased adsorption time as shown in Fig. $3 \mathrm{~d}$. The adsorption rates of Congo red all exceeded $45 \%$ during the initial sixty minutes, and then the increased slowly until 150 minutes. Because the time of physical adsorption was relatively short and the time of chemical adsorption was relatively long, along with the observation that high temperature was not conducive to the adsorption of Congo red, it was speculated that the adsorption process of Congo red could be a mixed adsorption process including physical adsorption and chemical adsorption.

From the above adsorption results, the brewer's grains with different pretreatments could all be used as efficient bio-adsorbents for the removal of Congo red in aqueous solutions, and the bio-adsorbent BGPOH should be better.

\section{Analysis of Adsorption Isotherm, Thermodynamics, and Kinetics}

The Langmuir, Freundlich, and Temkin models were used to analyze the adsorption isotherm (Araújo et al. 2018). The values of $\left(C_{e} / Q_{e}\right)$ were plotted against $C_{e}$ in the Langmuir model as shown in Fig. $4 \mathrm{a}$, the values of $\ln Q_{e}$ were plotted against $\ln C_{e}$ in the Freundlich model as shown in Fig. 4b, and the values of $Q_{e}$ were plotted against $\ln C_{e}$ in Temkin model as shown in Fig. 4c.

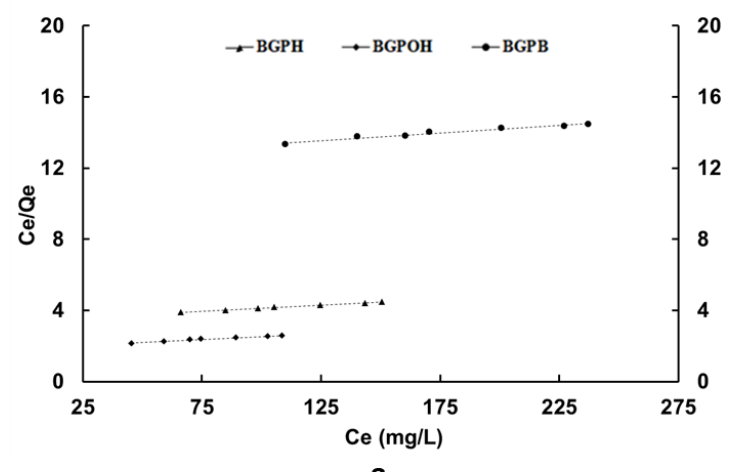

a

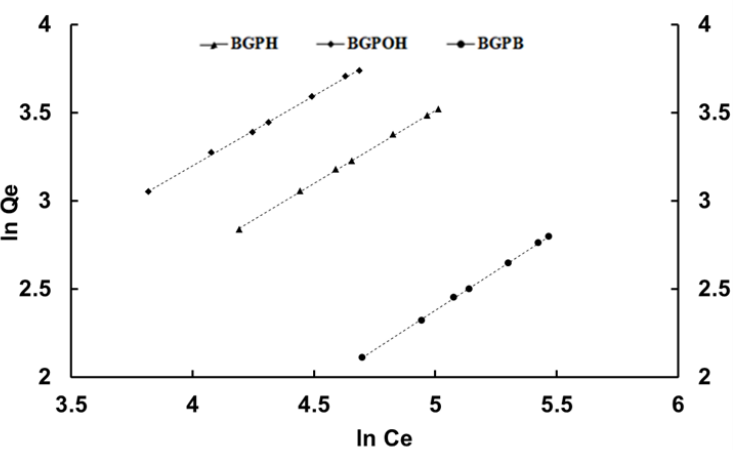

b

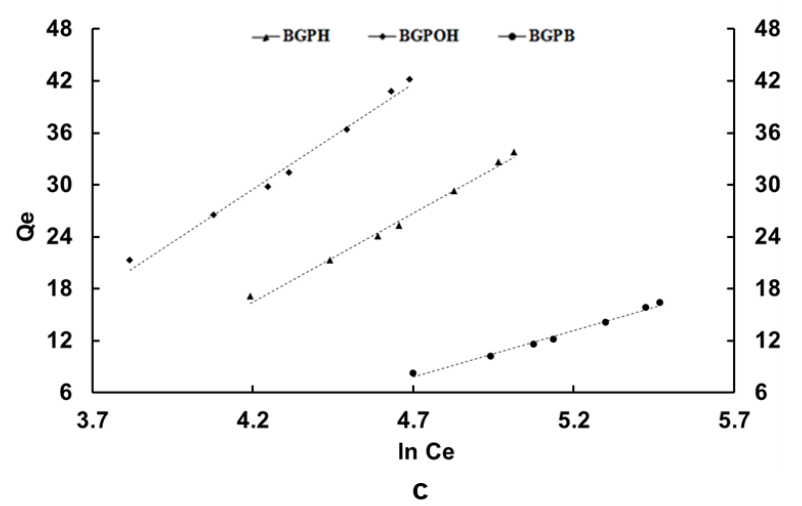

Fig. 4. Plots of Langmuir isotherms (a), Freundlich isotherms (b), and Temkin isotherms (c). The dashed lines were the linearized Langmuir, Freundlich, and Temkin models. 
The values of $K_{L}, Q_{m}, n, K_{F}, a_{t}$, and $b_{t}$ were calculated as shown in Table 2 using the slope and intercept of the trend fit lines, respectively. The regression coefficients $\left(\mathrm{R}^{2}\right)$ values were used to evaluate the fits of the Langmuir, Freundlich, and Temkin isotherm models to the experimental data.

Table 2. Coefficients of Langmuir, Freundlich, and Temkin Models Fitting for the Adsorption of Congo Red onto Bio-Adsorbents

\begin{tabular}{|c|c|c|c|c|c|c|c|c|c|c|}
\hline \multirow{2}{*}{$\begin{array}{c}\text { Bio- } \\
\text { adsorbent }\end{array}$} & \multicolumn{2}{|c|}{ Langmuir model } & \multicolumn{3}{c|}{ Freundlich model } & \multicolumn{3}{|c|}{ Temkin model } \\
\cline { 2 - 12 } & $\begin{array}{c}Q_{m \times 10^{-}} \\
(\mathrm{mg} / \mathrm{g})\end{array}$ & $\begin{array}{c}K_{L \times 10^{3}} \\
(\mathrm{~L} / \mathrm{mg})\end{array}$ & $\mathrm{R}^{2}$ & $n$ & $\begin{array}{c}K_{F} \\
(\mathrm{mg} / \mathrm{g}) \\
(\mathrm{L} / \mathrm{mg})^{1 / n}\end{array}$ & $\mathrm{R}^{2}$ & $a_{t} \times 10^{2}$ & $\begin{array}{c}b_{t} \times 10^{-} \\
2\end{array}$ & $\mathrm{R}^{2}$ \\
\hline BGPOH & 1.49 & 3.09 & 0.980 & 1.27 & 1.042 & 0.999 & 5.03 & 1.07 & 0.989 \\
\hline BGPH & 1.47 & 1.98 & 0.996 & 1.21 & 0.530 & 0.999 & 3.34 & 1.27 & 0.993 \\
\hline BGPB & 1.17 & 0.68 & 0.965 & 1.12 & 0.122 & 0.999 & 1.88 & 2.42 & 0.988 \\
\hline
\end{tabular}

As shown in Table 2, the maximum adsorption capacities $\left(Q_{m}\right)$ of Congo red onto BGPOH, BGPH, and BGPB obtained from the Langmuir model were $149 \mathrm{mg} / \mathrm{g}, 147 \mathrm{mg} / \mathrm{g}$, and $117 \mathrm{mg} / \mathrm{g}$, respectively, which indicated that the bio-adsorbents had good adsorption on Congo red, and BGPOH was the best bio-adsorbent. Values of " $n$ " obtained from the Freundlich model were all above 1, which indicated that there should be a potential good adsorption of Congo red onto the bio-adsorbents. Based on the alignment of the experimental data with the model lines in Fig. $4 \mathrm{a}, 4 \mathrm{~b}$, and $4 \mathrm{c}$, together with the $\mathrm{R}^{2}$ in Table 2 , the adsorption data of Congo red onto BGPOH, BGPH, and BGPB all fit well with the Langmuir, Freundlich, and Temkin models, and the adsorption of Congo red could take place mainly on the monolayer surface of the bio-adsorbent.

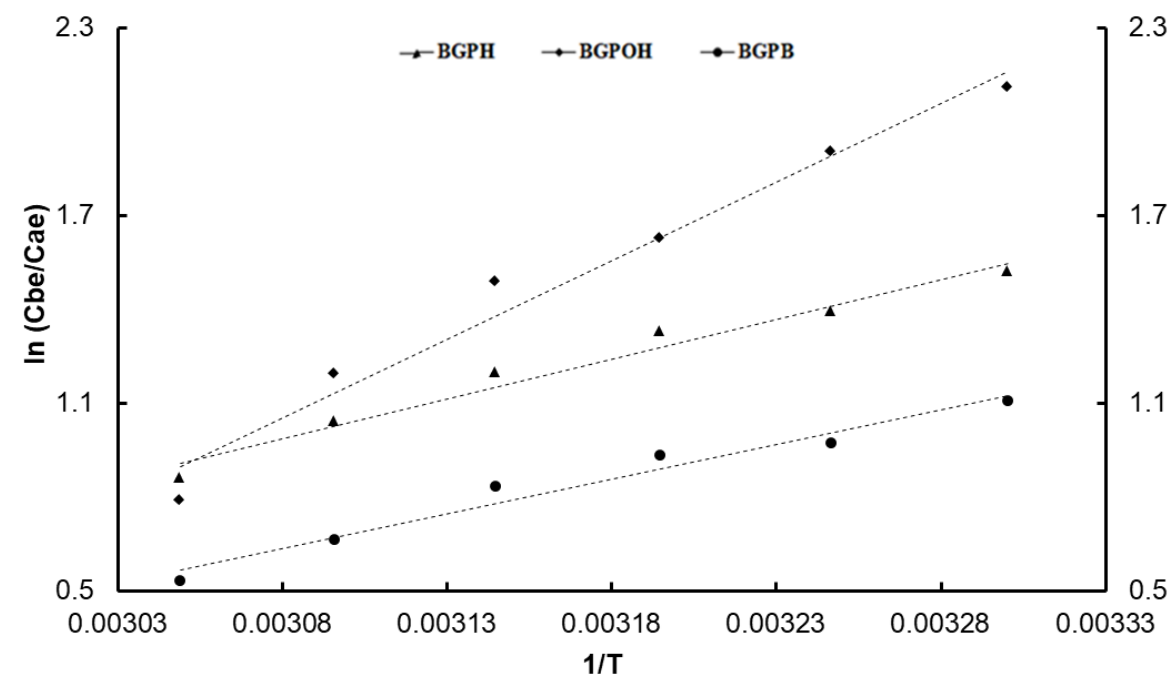

Fig. 5. Plots of adsorption thermodynamics. The dashed lines correspond to the linearized adsorption thermodynamics model 
Table 3. Enthalpy and Entropy Changes of Adsorption Thermodynamics Fitting for the Adsorption of Congo Red Onto Bio-Adsorbents

\begin{tabular}{|c|c|c|c|}
\hline Bio-adsorbent & $\Delta H \times 10^{-4}\left(\mathrm{~J}_{\mathrm{mol}}{ }^{-1}\right)$ & $\Delta S \times 10^{-1}\left(\mathrm{~J} \cdot \mathrm{mol}^{-1} \cdot \mathrm{K}^{-1}\right)$ & $\mathrm{R}^{2}$ \\
\hline BGPOH & -4.17 & -11.98 & 0.974 \\
\hline BGPH & -2.11 & -5.69 & 0.973 \\
\hline BGPB & -1.83 & -5.12 & 0.965 \\
\hline
\end{tabular}

Table 4. Gibbs Free Energy Change of Adsorption of Congo Red onto BioAdsorbents at Different Temperatures

\begin{tabular}{|c|c|c|c|c|c|c|}
\hline \multirow{2}{*}{ Bio-adsorbent } & \multicolumn{7}{|c|}{$\Delta G \times 10^{-3}\left({\left.\mathrm{~J} . \mathrm{mol}^{-1}\right)}\right.$} \\
\cline { 2 - 7 } & $303 \mathrm{~K}$ & $308 \mathrm{~K}$ & $313 \mathrm{~K}$ & $318 \mathrm{~K}$ & $323 \mathrm{~K}$ & $328 \mathrm{~K}$ \\
\hline BGPOH & -5.44 & -4.84 & -4.25 & -3.65 & -3.05 & -2.48 \\
\hline BGPH & -3.90 & -3.61 & -3.33 & -3.04 & -2.76 & -2.47 \\
\hline BGPB & -2.83 & -2.57 & -2.32 & -2.06 & -1.80 & -1.55 \\
\hline
\end{tabular}

The adsorption thermodynamics were analyzed by plotting $\ln \left(C_{B e} / C_{A e}\right)$ against temperature $(T)$ as shown in Fig. 5, and the values of $\Delta H, \Delta S$, and $\mathrm{R}^{2}$ are shown in Table 3 . The $\mathrm{R}^{2}$ values of the adsorption thermodynamics model of Congo red onto the bioadsorbents all exceeded 0.965, which indicated that the model was suitable for the adsorption of Congo red onto the bio-adsorbents. Based on the values of $\Delta H$ and $\Delta S$, the Gibbs free energy change $(\Delta G)$ was calculated as shown in Table 4 . The value of $\Delta G$ was always negative within the experimental temperature range from $303 \mathrm{~K}$ to $328 \mathrm{~K}$, which indicated that the adsorption was spontaneous (Roy and Mondal 2019). The absolute values of the $\Delta G$ of adsorption for Congo red onto BGPOH were all higher than that of BGPH and BGPB at the same temperature, which indicated that BGPOH could be more easily able to adsorb Congo red dye. The absolute values of $\Delta G$ decreased when temperature increased, which further indicated that lower temperature was useful for the adsorption of Congo red dye.

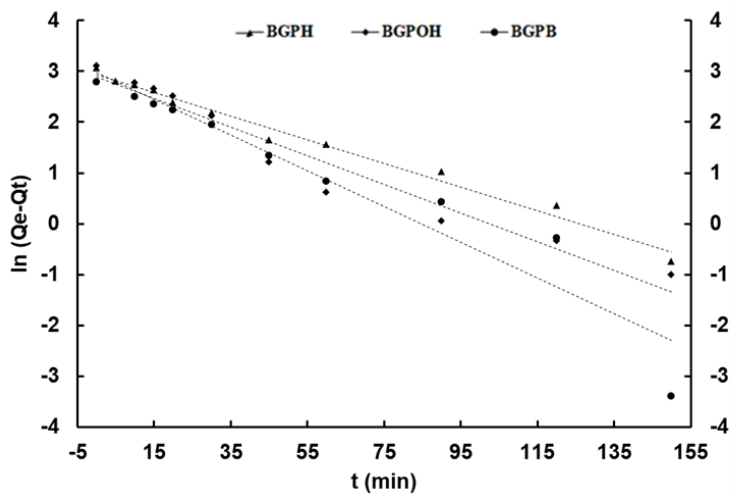

a

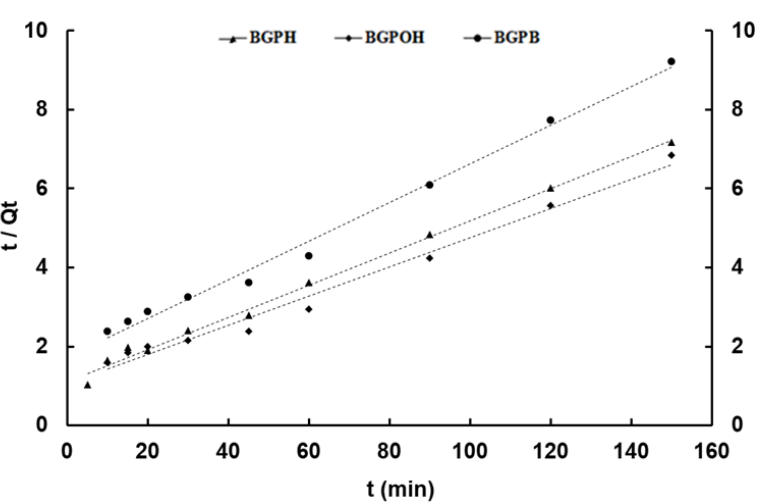

b

Fig. 6. Plots of first-order (a) and second-order (b) kinetics for Congo red adsorption onto bioadsorbents. The dashed lines are the linearized first-order and second-order kinetics models. 
Table 5. Coefficients of the First and Second Order Kinetic Models Fitted for the Adsorption of Congo Red onto Bio-adsorbents

\begin{tabular}{|c|c|c|c|c|c|c|}
\hline \multirow[b]{2}{*}{ Bio-adsorbent } & \multicolumn{3}{|c|}{ First order kinetic model } & \multicolumn{3}{|c|}{ Second order kinetic model } \\
\hline & $\begin{array}{c}Q e \times 10^{-1} \\
(\mathrm{mg} / \mathrm{g})\end{array}$ & $\begin{array}{l}k_{1 \times 10^{2}} \\
(1 / \mathrm{min})\end{array}$ & $\mathrm{R}^{2}$ & $\begin{array}{c}Q e \times 10^{-1} \\
(\mathrm{mg} / \mathrm{g})\end{array}$ & $\begin{array}{c}k_{2 \times 10^{3}} \\
(\mathrm{~g} / \mathrm{mg})(1 / \mathrm{min})\end{array}$ & $\mathrm{R}^{2}$ \\
\hline $\mathrm{BGPOH}$ & 1.81 & 2.83 & 0.954 & 2.70 & 1.29 & 0.984 \\
\hline BGPH & 1.89 & 2.33 & 0.985 & 2.46 & 1.49 & 0.995 \\
\hline BGPB & 1.96 & 3.51 & 0.918 & 2.04 & 1.39 & 0.992 \\
\hline
\end{tabular}

Adsorption kinetics can be evaluated by pseudo first-order and second-order kinetics models (Munagapati and Kim 2017). The values of $\ln \left(Q_{e}-Q_{t}\right)$ were plotted against time $(t)$ in a pseudo first order kinetic model, as shown in Fig. 6a, and the values of $t / Q_{t}$ were plotted against time $(t)$ in a pseudo second order kinetic model as shown in Fig. $6 \mathrm{~b}$. The values of $k_{1}, k_{2}$, and $Q_{e}$ are shown in Table 5. Based on the alignment of the experimental data with the model lines in Fig. $6 \mathrm{a}$ and $6 \mathrm{~b}$, together with the $\mathrm{R}^{2}$ in Table 5, the adsorption data of Congo red onto BGPOH, BGPH, and BGPB all fit well with the pseudo first-order and second-order kinetics models, but the second-order kinetics model fit better with an $R^{2}$ of $0.984,0.995$, and 0.992 , as compared to the first-order kinetics model with an $R^{2}$ of $0.954,0.985$, and 0.918 , respectively. This indicated that the secondorder kinetics model could be more suitable to describe the adsorption kinetics of Congo red onto the bio-adsorbents, and the adsorption of Congo red onto the adsorbents was controlled by diffusion phenomena (Hubbe et al. 2019).

\section{CONCLUSIONS}

1. Brewer's grains (BG), pretreated by sulfuric acid, sodium hydroxide, and white-rot fungus could be used as bio-adsorbents BGPH, BGPOH, and BGPB, respectively. The 3 adsorbents were rich in hydroxyl groups and could adsorb Congo red dye from aqueous solution, and BGPOH worked better than the others.

2. The Langmuir, Freundlich and Temkin models fit all well with the experimental data. The negative Gibbs free energy change meant the adsorption was spontaneous, and lower temperature was conducive for the adsorption.

3. The pseudo-second-order kinetics model fit with the experimental data better than the pseudo first-order model, indicating that the adsorption was controlled by diffusion phenomena.

\section{ACKNOWLEDGMENTS}

The authors are grateful for the support of the National Natural Science Foundation of China, Grant No. 31870543, and the Qinglan Project of Jiangsu Province of China.

\section{REFERENCES CITED}

Ahmed, M., Mashkoor, F., and Nasar, A. (2020). "Development, characterization, and 
utilization of magnetized orange peel waste as a novel adsorbent for the confiscation of crystal violet dye from aqueous solution," Groundwater for Sustain. Dev. 10, 100322. DOI:10.1016/j.gsd.2019.100322

Araújo, C. S. T., Almeida, I. L. S., Rezende, H. C., Marcionilio, S. M. L. O., Léon, J. J. L., and Matos, T. N. d. (2018). "Elucidation of mechanism involved in adsorption of $\mathrm{Pb}$ (II) onto lobeira fruit (Solanum lycocarpum) using Langmuir, Freundlich and Temkin isotherms," Microchem. J. 137, 348-354. DOI: 10.1016/j.microc.2017.11.009

Ashman, C. H., Gao, L., and Goldfarb, J. L. (2020). "Silver nitrate in situ upgrades pyrolysis biofuels from brewer's spent grain via biotemplating," J. Anal. Appl.Pyrol. 146, 104729. DOI: 10.1016/j.jaap.2019.104729

Awolu, O. O., Osemeke, R. O., and Ifesan, B. O. (2016). "Antioxidant, functional and rheological properties of optimized composite flour, consisting wheat and amaranth seed, brewers' spent grain and apple pomace," J. Food Sci. Technol. 53(2), 11511163. DOI: $10.1007 / \mathrm{s} 13197-015-2121-8$

Azlinda, A. G., Ragunathan, S., Tunku, A. Z. T. O., Sam, S. T., and Hanafi, I. (2016). "Chemical reaction and morphology of polypropylene (PP)/recycled acrylonitrile butadiene rubber (NBRr)/banana skin powder (BSP) composites with $\gamma$-APS," $A d v$. Mater. Res. 1133, 175-179. DOI: 10.4028/www.scientific.net/AMR.1133.175

Birsan, R. I., Wilde, P., Waldron, K. W., and Rai, D. K. (2019). "Recovery of polyphenols from brewer's spent grains," Antioxidants (Basel), 8(9), 380. DOI: 10.3390/antiox 8090380

Bougrier, C., Dognin, D., Laroche, C., and Cacho Rivero, J. A. (2018). "Use of trace elements addition for anaerobic digestion of brewer's spent grains," J. Environ. Manage. 223, 101-107. DOI: 10.1016/j.jenvman.2018.06.014

Chanzu, H. A., Onyari, J. M., and Shiundu, P. M. (2019). "Brewers' spent grain in adsorption of aqueous Congo Red and malachite Green dyes: Batch and continuous flow systems," J. Hazard Mater. 380, 120897. DOI: 10.1016/j.jhazmat.2019.120897

Chu, Q., Song, K., Hu, J., Bu, Q., Zhang, X., and Chen, X. (2019). "Integrated process for the coproduction of fermentable sugars and lignin adsorbents from hardwood," Bioresource Technol. 289, 121659. DOI: 10.1016/j.biortech.2019.121659

Dou, R., Cheng, H., Ma, J., and Komarneni, S. (2020). "Manganese doped magnetic cobalt ferrite nanoparticles for dye degradation via a novel heterogeneous chemical catalysis," Mater. Chem. Phys. 240, 122181. DOI: 10.1016/j.matchemphys.2019.122181

Godlewska, P., Siatecka, A., Kończak, M., and Oleszczuk, P. (2019). "Adsorption capacity of phenanthrene and pyrene to engineered carbon-based adsorbents produced from sewage sludge or sewage sludge-biomass mixture in various gaseous conditions," Bioresource Technol. 280, 421-429. DOI: 10.1016/j.biortech.2019.02.021

Goswami, M., Chaturvedi, P., Sonwani, R. K., Gupta, A. D., Singhania, R. R., Giri, B. S., Rai, B. N., Singh, H., Yadav, S., and Singh, R. S. (2020). "Application of Arjuna (Terminalia arjuna) seed biochar in hybrid treatment system for the bioremediation of Congo red dye," Bioresource Technol. 307, 123203. DOI: 10.1016/j.biortech.2020.123203

Hassona, H. Z. (1993). "High fibre bread containing brewer's spent grains and its effect on lipid metabolism in rats," Food/Nahrung 37(6), 576-582. DOI: 10.1002/food.19930370609

Hubbe, M. A., Azizian, S., and Douven, S. (2019). "Implications of apparent pseudo- 
second-order adsorption kinetics onto cellulosic materials. A review," BioResources 14(3), 7582-7626. DOI: 10.15376/biores.14.3.7582-7626

Imaizumi, H., Batistel, F., de Souza, J., and Santos, F. A. (2015). "Replacing soybean meal for wet brewer's grains or urea on the performance of lactating dairy cows," Trop. Anim. Health Prod. 47(5), 877-882. DOI: 10.1007/s11250-015-0802-y

Katheresan, V., Kansedo, J., and Lau, S. Y. (2018). "Efficiency of various recent wastewater dye removal methods: A review," J. Environ. Chem. Eng. 6(4), 46764697. DOI: 10.1016/j.jece.2018.06.060

Ktenioudaki, A., O'Shea, N., and Gallagher, E. (2013). "Rheological properties of wheat dough supplemented with functional by-products of food processing: Brewer's spent grain and apple pomace," J. Food Eng. 116, 362-368. DOI:

10.1016/j.jfoodeng.2012.12.005

Lao, E. J., Dimoso, N., Raymond, J., and Mbega, E. R. (2020). "The prebiotic potential of brewers' spent grain on livestock's health: A review," Trop. Anim. Health Prod. 52(2), 461-472. DOI: $10.1007 / \mathrm{s} 11250-019-02120-9$

Li, Z., Hanafy, H., Zhang, L., Sellaoui, L., Netto, M. S., Oliveira, M. L. S., Seliem, M. K., Dotto, G. L., Bonilla-Petriciolet, A., and Li, Q. (2020). "Adsorption of congo red and methylene blue dyes on an ashitaba waste and a walnut shell-based activated carbon from aqueous solutions: Experiments, characterization and physical interpretations," Chem. Eng. J. 388, 124263. DOI: 10.1016/j.cej.2020.124263

Lorente, A., Remón, J., L.Budarin, V., Sánchez-Verdú, P., Moreno, A., and Clark, J. H. (2019). "Analysis and optimisation of a novel "bio-brewery" approach: Production of bio-fuels and bio-chemicals by microwave-assisted, hydrothermal liquefaction of brewers' spent grains," Energy Convers. Manage. 185, 410-430. DOI: 10.1016/j.enconman.2019.01.111

Low, K. S., Lee, C. K., and Liew, S. C. (2000). "Sorption of cadmium and lead from aqueous solutions by spent grain," Process Biochem. 36, 59-64. DOI: 10.1016/S00329592(00)00177-1

Mahmood, A. S. N., Brammer, J. G., Hornung, A., Steele, A., and Poulston, S. (2013). "The intermediate pyrolysis and catalytic steam reforming of brewers spent grain," $J$. Anal. Appl. Pyrol. 103, 328-342. DOI: 10.1016/j.jaap.2012.09.009

McCarthy, A. L., O'Callaghan, Y. C., Piggott, C. O., FitzGerald, R. J., and O'Brien, N. M. (2013). "Brewers' spent grain; bioactivity of phenolic component, its role in animal nutrition and potential for incorporation in functional foods: A review," Proc. Nutr. Soc. 72(1), 117-125. DOI: 10.1017/S0029665112002820

Munagapati, V. S., and Kim, D. S. (2017). "Equilibrium isotherms, kinetics, and thermodynamics studies for congo red adsorption using calcium alginate beads impregnated with nano-goethite," Ecotox. Environ. Safe. 141, 226-234. DOI: 10.1016/j.ecoenv.2017.03.036

Mussatto, S. I., Moncada, J., Roberto, I. C., and Cardona, C. A. (2013). "Technoeconomic analysis for brewer's spent grains use on a biorefinery concept: the Brazilian case," Bioresource Technol. 148, 302-310. DOI: 10.1016/j.biortech.2013.08.046

Oliveira, J. M. S., Silva, M. R. d. L., Issa, C. G., Corbi, J. J., Damianovic, M. H. R. Z., and Foresti, E. (2020). "Intermittent aeration strategy for azo dye biodegradation: A suitable alternative to conventional biological treatments?" J. Hazard. Mater. 385, 121558. DOI: 10.1016/j.jhazmat.2019.121558

Rojas-Chamorro, J. A., Romero-Garcia, J. M., Cara, C., Romero, I., and Castro, E. 
(2020). "Improved ethanol production from the slurry of pretreated brewers' spent grain through different co-fermentation strategies," Bioresource Technol. 296, 122367. DOI: $10.1016 /$ j.biortech.2019.122367

Roy, T. K., and Mondal, N. K. (2019). "Potentiality of Eichhornia shoots ash towards removal of Congo red from aqueous solution: Isotherms, kinetics, thermodynamics and optimization studies," Groundwater Sustain. Dev. 9, 100269. DOI: 10.1016/j.gsd.2019.100269

Sun, R., Zhu, H., Shi, M., Luo, G., Xu, Y., Li, X., and Yao, H. (2020). "Preparation of fly ash adsorbents utilizing non-thermal plasma to add $\mathrm{S}$ active sites for $\mathrm{HgO}$ removal from flue gas," Fuel 266, 116936. DOI: 10.1016/j.fuel.2019.116936

Tsai, W. T., Hsien, K. J., and Yang, J. M. (2004). "Silica adsorbent prepared from spent diatomaceous earth and its application to removal of dye from aqueous solution," $J$. Colloid Interf. Sci. 275(2), 428-433. DOI: 10.1016/j.jcis.2004.02.093

Wang, K. L., Lu, Z. M., Mao, X., Chen, L., Gong, J. S., Ren, Y., Geng, Y., Li, H., Xu, H. Y., Xu, G. H., Shi, J. S., Xu, Z. H. (2019). "Structural characterization and antialcoholic liver injury activity of a polysaccharide from Coriolus versicolor mycelia," Int. J. Biol. Macromol. 137, 1102-1111. DOI: 10.1016/j.ijbiomac.2019.06.242

White, J. S., Yohannan, B. K., and Walker, G. M. (2008). "Bioconversion of brewer's spent grains to bioethanol," FEMS Yeast Res. 8(7), 1175-1184. DOI: 10.1111/j.15671364.2008.00390.x

Wierzba, S., Rajfur, M., Nabrdalik, M., and Kłos, A. (2019). "Assessment of the influence of counter ions on biosorption of copper cations in brewer's spent grain Waste product generated during beer brewing process," Microchem. J. 145, 196-203. DOI: 10.1016/j.microc.2018.10.040

Wu, J., Xia, A., Chen, C., Feng, L., Su, X., and Wang, X. (2019). "Adsorption thermodynamics and dynamics of three typical dyes onto bio-adsorbent spent substrate of Pleurotus eryngii," Int. J. Environ. Res. Public Health 16, 679. DOI: 10.3390/ijerph16050679

Wu, J., Zhang, T., Chen, C., Feng, L., Su, X., Zhou, L., Chen, Y., Xia, A., and Wang, X. (2018). "Spent substrate of Ganodorma lucidum as a new bio-adsorbent for adsorption of three typical dyes," Bioresource Technol. 266, 134-138. DOI: 10.1016/j.biortech.2018.06.078

Xu, X., Zhou, C., Zhang, S., Cheng, Z., Yang, Z., Xian, J., and Yang, Y. (2019). "Adsorption of $\mathrm{Cr}^{6+}$ and $\mathrm{Pb}^{2+}$ on Soy Sauce Residue Biochar from Aqueous Solution," BioResources 14(2), 4653-4669. DOI: 10.15376/biores.14.2.4653-4669

Zhang, J., and Zang, L. (2016). "Enhancement of biohydrogen production from brewers' spent grain by calcined-red mud pretreatment," Bioresource Technol. 209, 73-79. DOI: 10.1016/j.biortech.2016.02.110

Article submitted: May 24, 2020; Peer review completed: July 12, 2020; Revised version received and accepted: July 14, 2020; Published: July 22, 2020.

DOI: 10.15376/biores.15.3.6928-6940 